\title{
Excess Volumes, Viscosities and Refractive Index for the Binary Mixtures of Acetophenone, Cyclopentanone, Cyclohexanone and 3-pentanone with Dibutyl Maleate at $T=(303.15,308.15$ and 313.15) K
}

\author{
M.V. Rathnam ${ }^{1}$, Sudhir Mohite ${ }^{2}$, M. Nandini ${ }^{3}$ \\ ${ }^{1,2}$ (Physical Chemistry Research Laboratory, B.N. Bandodkar College of Science; Thane - 400 601, India \\ Email:mvrathnam58@rediffmail.com,sudhirmohite82@gmail.com) \\ ${ }^{3}$ (Department of Chemistry, Dr. P. R. Ghogrey Science College, Deopur, Dhule-424005, India \\ Email:m.nandinikumar@gmail.com)
}

\begin{abstract}
Density, viscosity and refractive index of some binary mixtures of dibutyl maleate with acetophenone, cyclopentanone, cyclohexanone, and 3-pentanone have been measured over the entire composition range at (303.15, 308.15 and 313.15$) \mathrm{K}$ and at atmospheric pressure. Excess volume $\left(V^{E}\right)$ and deviation in viscosity $(\Delta \eta)$ have been estimated from the experimental data of density and viscosity. The results of excess properties are interpreted in terms of molecular interactions. These results were fitted to Redlich-Kister polynomial equation to estimate the binary coefficients and standard errors. Further the values of $\left(V^{E}\right)$ have been analyzed using Prigogine-FloryPatterson (PFP) theory. Refractive index composition data are discussed in the light of various equations suggested by Lorentz-Lorentz, Weiner and Newton. The mixture viscosities have also been correlated using Auslaender and Krishnan-Laddha models.

Keywords: Excess volume, Viscosity, Refractive Index, Dibutyl Maleate, Molecular interactions
\end{abstract}

\section{INTRODUCTION}

Thermodynamic data on density, viscosity are mostly essential for any industrial process as they find several practical applications [1,2]. The excess or deviation properties obtained from such thermodynamic data enable us to understand the molecular interactions involving in liquid-liquid mixtures [3]. Dibutyl maleate has been selected owing to its importance as an additive and intermediate for plastics, pigments, pharmaceuticals and agricultural products. Dibutyl maleate is used in the manufacturing of paints giving them a higher flexibility, stability to water and ultra violet light besides a higher adherence, plasticizer in water resistant film. Now days it can be used as gelatin accelerator and anti-corrosive additive. To the best of our knowledge there are no reports on thermophysical properties for the binary mixtures of dibutyl maleate with ketones. This is mainly motivated us to undertake the present study.

In continuation of our program of research on the physicochemical properties of binary nonelectrolyte liquid mixtures of esters [4-6]. We report here experimental densities $(\rho)$, viscosities $(\eta)$, and refractive indices $\left(n_{\mathrm{D}}\right)$ for dibutyl maleate + acetophenone, + cyclopentanone, + cyclohexanone and +3 -pentanone at $(303.15,308.15$ and 313.15) K over the entire range of mixture composition at atmospheric pressure. The aim of this work is to investigate the applicability of Prigogine-FloryPatterson (PFP) theory to the excess volume and also to analyze applicability of the three parameter viscosity models of Auslaender and Krishnan-Ladha and the refractive index models viz. Loretz-Lorentz, Weiner and Newton.

\subsection{Materials}

\section{EXPERIMENTAL}

All the liquids used in the present study were purified by standard methods [7]. The mole fraction of purity was better than 0.995 for all the liquids and they were stored in dark bottles to prevent contamination from air and dried over 4A molecular sieves. The purity of the solvents was finally checked on GLC and the final purity was found to be better than 99.8 mole $\%$. 


\subsection{Apparatus and Procedures}

Mixtures of different compositions were prepared for each binary system in airtight bottles. Mass measurements accurate to $\pm 0.01 \mathrm{mg}$ were made on digital electronic balance (Mettler, AE 240 Switzerland). The uncertainty in the mole fraction thus estimated was found to be less than $\pm 1 \times 10^{-4}$. Densities of pure liquids and their binary mixtures were determined using a Rudulph research analytical digital densimeter (DDH-2910 USA). The instrument calibration has been described earlier [8]. The uncertainty in the density measurement was found to be $\pm 3 \times 10^{-4} \mathrm{~g} . \mathrm{cm}^{-3}$. The viscosities of pure liquids and their mixtures were determined using an Ubbelhode viscometer. The flow time of each sample was measured by suspending viscometer in a low temperature viscometer bath (Cat No: KVB-04/SP, Sr. No: 2KX-03-375, Watts 1500, Volts 1-230) supplied by S. Kumar Mumbai, India. The temperature of the viscometer bath was controlled within $\pm 0.01 \mathrm{~K}$. The uncertainty in dynamic viscosities is of the order of $\pm 0.003 \mathrm{mPa}$.s. Refractive indices of pure liquids and their mixtures were measured using a refractometer (RM40, Metteler Toledo, Switzerland) with an uncertainty of \pm 0.0004 . The instrument has built-in solid state thermostat of temperature range $\left(5\right.$ to $\left.100^{\circ} \mathrm{C}\right)$ with an uncertainty of $\pm 0.1^{\circ} \mathrm{C}$. The calibration of the instrument was carried out by dry air and water at a required temperature.

\section{RESULTS AND DISCUSSION}

The experimental values of densities $(\rho)$, excess volumes $\left(V^{E}\right)$, viscosities $(\eta)$, refractive indices $\left(n_{\mathrm{D}}\right)$ of at $(303.15,308.15$ and 313.15$) \mathrm{K}$ are listed as a function of mole fraction in Table 1 . The density values have been used to calculate excess volumes $V^{E}$ using the following relation

$V^{E}=\left(x_{1} M_{1}+x_{2} M_{2}\right) / \rho-\left(x_{1} M_{1} / \rho_{1}+x_{2} M_{2} / \rho_{2}\right)$

Where $\rho$ is the density of the mixture and $\left(x_{1}, M_{1}\right.$ and $\left.\rho_{1}\right)$ and $\left(x_{2}, M_{2}\right.$ and $\left.\rho_{2}\right)$ are the mole fractions, molar masses, and densities of pure components 1 and 2 respectively. The variation in excess volume with mole fraction of the studied binary mixtures is displayed in Fig.1. The $V^{E}$ values are found to be negative over the entire range of composition exhibiting negative curves. The $V^{E}$ of mixtures is mostly influenced by chemical, structural and physical effects. The close observation of Fig.1 indicates that molecular interactions between ester and ketones are most favored in the region of $x_{1}=0.5$ with minima. This may be attributed to variable size and shapes of acetophenone, cyclopentanone, cyclohexanone and 3-pentanone molecules causing strong interactions with ester molecule. In the present study the negative $V^{E}$ values may indicate that volume reducing factors are dominant over the expansion factors. Fig. 2 shows that deviation in viscosity $(\Delta \eta)$. The viscosity deviations $\Delta \eta$ were calculated using the relation

$\Delta \eta=\eta-\left(x_{1} \eta_{1}+x_{2} \eta_{2}\right)$

where $\eta$ is the dynamic viscosity of the mixture and $\eta_{1}$ and $\eta_{2}$ are the viscosities of pure components respectively.

The excess molar volumes and the deviations in the viscosities were fitted to Redlich-Kister [9] equation of the type

$\Delta y=x_{1}\left(1-x_{1}\right) \sum_{i=0}^{n} \quad \mathrm{~A}_{i}\left(2 x_{1}-1\right)^{i}$

Where $\Delta y$ is either $V^{E}$ or $\Delta \eta$ and ' $n$ ' is the degree of polynomial. Coefficients $\mathrm{A}_{i}$ were obtained by fitting equation (3) to experimental results using a least squares regression method. In each case, the optimum number of coefficients is ascertained from an examination of the variation in standard deviation $(\sigma)$. The variation in standard deviations $(\sigma)$ was calculated by using the relation

$\sigma(y)=\left[\Sigma\left(y_{\text {obs }}-y_{\text {cal }}\right)^{2} /(n-m)\right]^{1 / 2}$

where ' $n$ ' represents the number of data points and ' $m$ ' is the number of coefficients. The calculated values of the polynomial coefficients along with their standard deviations $(\sigma)$ are given in Table 2. It is observed that the $\Delta \eta$ values are negative for mixtures of acetophenone and 3-pentanone, while for mixtures of cyclopentanone and cyclohexanone $\Delta \eta$ values are completely positive over the entire mole fraction range of dibutyl maleate. Further it is observed that the values are more negative for 3-pentanone and less negative for acetophenone. However the negative deviation decreases with increase in temperature. Likewise for mixtures of cyclopentanone the $\Delta \eta$ values are less positive as compared to cyclohexanone indicating the effect of temperature on mixtures. A close observation of Fig. 1 and 2 reveals that the isotherms do not follow common trend indicating a clear idea that the strength of specific or dispersion forces is not the only factor influencing the deviation in mixture viscosities [10]. The shape and size of the liquid components are also responsible factors.

\subsection{Correlation of Mixture Viscosities:}

Molecular models have been developed and utilized to obtain further understanding of liquid mixture viscosity. Generally the models have been 
indicative that interaction terms are essential in prediction of mixture viscosity behavior. Unfortunately determination of the interaction terms has been by data fitting and so the shortcomings of these models are similar to the correlations except that at least the adjustable parameters have some physical interpretation. Reid et al [11] and Monnery et al [12] have reviewed several mixture viscosity models to correlate the mixture viscosities. In this report we have correlated the experimental mixture viscosities using the Auslaender and KrishnanLaddha models.

\subsubsection{Auslaender model:}

Auslaender [13 ] proposed a suitable equation for experiemental viscosity data as

$\eta=\eta_{1} x_{1}\left(x_{1}+B_{12} x_{2}\right)+\eta_{2}\left(A_{21} x_{2}\left(B_{21} x_{1}+x_{2}\right)\right) / x_{1}\left(x_{1}\right.$ $\left.+B_{12} x_{2}\right)+\left(A_{21} x_{2}\right)\left(B_{21} x_{1}+x_{2}\right)$

Where $A_{21}, B_{12}$ and $B_{21}$ are parameters representing the binary specific interactions and could be calculated by a least square procedure.

\subsubsection{Krishnan-Laddha model:}

The equation proposed by Krishnan-Laddha [14] is based on Eyring's theory of absolute reaction rates [15]. The kinematic viscosities of the binary systems were correlated using following equation

$\ln v=x_{1} \ln v_{1}+x_{2} \ln v_{2}+x_{1} \ln M_{1}+x_{2} \ln M_{2}-\ln \left[\left(x_{1} M_{1}\right.\right.$ $\left.+x_{2} M_{2}\right)-2.303 x_{1} x_{2}\left[B_{12}+C_{12}\left(x_{1}-x_{2}\right)+\right.$

$\left.\left.D_{12}\left(x_{1}-x_{2}\right)^{2}\right]\right]$

Where $M_{1}$ and $M_{2}$ are molar mass of the pure component and $B_{12}, C_{12}, D_{12}$ are the binary viscosity coefficients. The last term of this equation called as the excess free energy of activation for the flow takes into account the deviation of data of binary liquid mixtures from the linear additive behavior of the pure component viscosities.

The predictive abilities of above models was tested by calculating the standard percentage deviation $\sigma(\%)$ between the experimental $\left(\eta_{\text {expt }}\right)$ and calculated $\left(\eta_{\text {cal }}\right)$ viscosities as

$$
\sigma(\%)=\left[\frac{1}{n-k} \sum\left\{\frac{100\left(\eta_{\text {expt }}-\eta_{\mathrm{cal}}\right)}{\eta_{\mathrm{expt}}}\right\}^{2}\right]^{1 / 2}
$$

where ' $n$ ' represents the number of data points in each set and ' $k$ ' the number of numerical coefficients in the equations. $\eta_{\text {cal }}$ has been obtained from model equations (5 and 6). The calculated interaction parameters of equations (5 and 6) and $\sigma(\%)$ values are given in Table 3 . Analysis of these values reveals that for Auslaender model, the $\sigma(\%)$ values are in the range of (0.02-0.91) with average $\sigma(\%)$ value as 0.323 . While for Krishnan-Laddha model, the $\sigma(\%)$ values are in the range of $(0.02-2.60)$ with average $\sigma(\%)$ value as 0.982 for the studied binary systems. From the analysis of $\sigma(\%)$ values it is evident that Auslaender model predicts the experiemental mixture viscosities more satisfactorily than Krishnan-Laddha model.

\subsection{Applications of Refractive Index Mixing Rules:}

Refractive index is a fundamental physical property of a substance. It is often used to identify a particular substance, confirm its purity, or measure its concentration. There have been several theoretical mixing rules for predicting the refractive index of binary liquid mixtures. Pandey et al [16] have discussed the significance of such mixing rules. Among the various mixing rules the most widely used refractive mixing rules are of Lorentz-Lorentz and Weiner. In the present report we have applied the following mixing rules for the analysis of our experimental refractive index data.

\subsubsection{Lorentz-Lorentz $[17,18]$}

$\left[n_{12}{ }^{2}-1 / n_{12}{ }^{2}+2\right]=\left[n_{1}{ }^{2}-1 / n_{1}{ }^{2}+2\right] \Phi_{1}+\left[n_{2}{ }^{2}-1 / n_{2}{ }^{2}\right.$
$+2] \Phi_{2}$

3.2.2 Weiner $[17,18]$

$\left[n_{12}{ }^{2}-n_{1}^{2} / n_{12}^{2}+2 n_{1}^{2}\right]=\left[n_{2}^{2}-n_{1}^{2} / n_{2}^{2}+2 n_{1}^{2}\right]$

3.2.3 Newton [19]

$n_{12}^{2}-1=\left(n_{1}^{2}-1\right) \Phi_{1}+\left(n_{2}^{2}-1\right) \Phi_{2}$

Where $n_{12}$ is the refractive index of the binary mixture. $\Phi_{1}$ and $\Phi_{2}$ are the volume fractions, and $n_{1}$, $n_{2}$ are the refractive index of pure components 1 and 2 respectively. The predictive ability of equations (8-10) has been tested by calculating the average percentage deviation (APD) between the experimental and calculated values using the following relation

$\mathrm{APD}=100 \sum_{i=1}^{n}\left|n_{D \exp }-n_{D \mathrm{cal}}\right| / \mathrm{n}$

Where ' $n$ ' is the number of data points. The values of average percentage deviations of the investigated mixtures are given in Table 4 . A perusal of refractive index data reveals that these $n_{D}$ values decrease with increase in temperature for all the binary liquid mixtures. This decrease may be attributed to the decrease in densities with increase in temperature. Similar behavior has also been observed by 
Bhatia et al [20], Mehra et al [21] and Navendra et al [22] in their respective studies. Isehunwa et al [23] have also attributed these changes in refractive index to the structural changes which occur during mixing. A close examination of APD values Table 4 reveals that Weiner relation with low APD values predicts $n_{D}$ more satisfactorily as compared to Lorentz-Lorentz and Newton relation. The APD values predicted by Newton relation are very large and follow the order Weiner < Lorentz-Lorentz < Newton

Furthermore it was observed that the refractive index values predicted by the studied mixing rules have exactly follow the same trends as that of experimental values, which support the experimental observations.

\subsection{Prigogine-Flory-Patterson Theory:}

The Prigogine-Flory-Patterson (PFP) theory was used to correlate the $V^{\mathrm{E}}$ results for the studied binary mixtures. The details pertaining to PFP theory and different contributions have been reported earlier [24]. The parameters involved for the pure components are obtained by PFP theory and are represented in Table 5. While the values of three contributions of PFP theory to $V^{E}$ and the calculated $V^{E}$ data at $x_{1}=0.5$ along with experimental equimolar values of $V^{\mathrm{E}}$ for each of the binary mixture at the studied temperatures are given in Table 6.

A perusal of Table 6 reveals that the interactional contribution $V^{E}$ (int), and the free volume $V_{(\mathrm{fv})}^{E}$ contribution are positive, while the internal pressure $V^{E}{ }_{(\text {ip) }}$ contribution values are negative for the liquid mixtures investigated. Moreover comparison between $V^{E}$ (expt) and $V_{(\mathrm{PFP})}^{E}$ is made by calculating $V_{(\text {PFP) }}^{E}$ values using $\chi_{12}$ at equimolar composition. On the basis of the present analysis it may be concluded that PFP theory satisfactorily predicts $V^{\mathrm{E}}$ values for the binary systems of acetophenone and 3-pentanone with dibutyl maleate. Whereas for cyclopentanone and cyclohexanone studied binary mixtures the predicted $V^{\mathrm{E}}$ values are larger than the experimental values.

\section{CONCLUSION}

The values of densities, viscosities and refractive indices at $(303.15,308.15$ and 313.15$) \mathrm{K}$ have been determined over the entire composition range for the binary mixtures of dibutyl maleate with acetophenone, cyclopentanone, cyclohexanone and 3 -pentanone. From the experimental data excess volume and deviation in viscosity have been calculated. The data of excess properties showed excellent agreement with Redlich-Kister polynomial.
Both positive and negative deviations are observed for deviation in viscosity, while the deviations in excess volumes show completely negative deviations. The Prigogine-Flory-Patterson (PFP) theory applied to the excess volume data correctly predicts the sign of $V^{E}$ values for all the studied mixtures. The PFP theory predicts the $V^{E}$ values satisfactorily for mixtures of acetophenone and 3-pentanone, while for cyclopentanone and cyclohexanone it predicts values with large difference. Viscosity results were analyzed by using Auslaender and Krishnan-Laddha models. It was observed that Auslaender model predicts the mixture viscosities with low percentage standard deviations as compared to Krishnan-Laddha. The refractive indices of binary mixtures were correlated theoretically from pure component data by using the mixing rules. It was observed that Weiner relation predicts the refractive indices reasonably well. The overall molecular interactions study for binary mixtures of dibutyl maleate with linear, cyclic and aromatic ketones exhibit strong interactions. Hence it may be concluded that size, shape, specific or dispersion forces of components are important factors in molecular interactions between liquid mixtures.

\section{ACKNOWLEDGEMENT}

The authors are thankful to Dr (Mrs.) Madhuri K. Pejaver, Principal, B. N. Bandodkar College of Science, Thane (India), for providing necessary facilities in the physical chemistry research laboratory.

\section{REFERENCES}

[1] M. C. S. Subha, G. Narayana Swamy, M. Eswaribhai, K.S. V. Krishna Rao, Excess volume and viscosity of ethoxy ethanol and nbutylamine, sec-butylamine, tert-butylamine, n-hexylamine, n-octylamine, and cyclohexylamine, Indian J. Chem, 43A, 2004, 1876-1881.

[2] R. Baskaran, T. R. Kubendran, Thermophysical Properties of paraAnisaldehyde (1) + Chlorobenzene (2) at Temperatures of $(303.15,313.15$, and 323.15) K and a Pressure of 0.1 MPa, J. Chem. Eng. Data, 53, 2008, 978-982.

[3] A. K. Nain, A. Ali, M. Alam, Excess molar volumes of (dimethylsulfoxide + propan-2-ol, or propan-1, 2-diol, or propan-1,2,3-triol) at $T=303.15$ K, J. Chem. Thermodyn, 30, 1998, 1275-1278.

[4] M. V. Rathnam, S. Mohite, M. S. S. Kumar, Densities, Viscosities, and Refractive Indices of Binary Mixtures of Diethyl Oxalate with 
Some Ketones at $(303.15,308.15$ and 313.15$)$ K, J. Chem. Eng. Data, 55, 2010, 5946-5952.

[5] M. V. Rathnam, S. Mohite, M. S. S. Kumar, Thermophysical Properties of binary mixtures (dimethyl carbonate + ketones) at $\mathrm{T}=(303.15$, 308.15 and 313.15) K, J. Mol. Liq, 163, 2011, 170-177.

[6] M. V. Rathnam, S. Mohite, M. S. S. Kumar, Volumetric, viscometric and optical study of molecular interactions in binary mixtures of diethyl malonate with ketones at $\mathrm{T}=(303.15$, 308.15 and 313.15) K, J. Serb. Chem. Soc, 77(4), 2012, 507-521.

[7] J.A. Riddick, W.B. Bunger, T.K. Sakano, Organic Solvents, Physical Properties and Methods of Purifications, 2, (WileyInterscience, New York, 1986).

[8] M. V. Rathnam, S. Mohite, M. S. S. Kumar, S. Dharap, Interaction study on Diethyl Maleate + Ketone Binary Mixtures: Application of PFP theory to Excess Volumes, Int. J. Sci. Eng. \& Applied Science, 1, 2015, 88-109.

[9] O. Redlich, A.T. Kister, Algebraic Representation of thermodynamic properties and the classification of solution, Ind. Eng. Chem, 40, 1948, 345-348.

[10] T. Savitha Jyostna, N. Suryanarayana, Densities and Viscosities of binary liquid systems of acetonitrile with aromatic ketones at $308.15 \mathrm{~K}$, Indian J. Chem, 44(A), 2005, 1365-1371.

[11] R. C. Reid, J. M. Prausnitz, B. E. Poling, The Properties of Gases and Liquids, Chapter 9 (McGraw-Hill, New York 1987), 474.

[12] W. D. Monnery, W.Y. Svrcek, A.K. Mehrotra, Viscosity: A critical review of practical predictive and correlative methods, Can. J. Chem. Eng, 77(4), 2012, 507-521.

[13] G. Auslaender, The Properties of Mixtures, Brit. Chem. Eng, 9, 1964, 610-616.

[14] M.R.V. Krishnan, G.S, Laddha, Viscosities of Binary Liquid Mixtures. Prediction from Y-X Data, Ind. Eng. Chem. Fundamen, 7, 1968, 324-327.

[15] S. Glasstone, K. L. Laidler, H. Eyring, Theory of Rate Process (McGraw Hill, New York, USA, 1941).

[16] J. D. Pandey, R. D. Rai, R. K. Shukla, K. P. Tiwari, A. K. Shukla, Relative validity of refractive index mixing rules for multicomponent systems, Indian J. Pure and Appl. Phys, 30, 1992, 94-96.

[17] T. M. Aminabhavi, H. T. S. Phayade, R. S Khinnavar, B. Gopalkrishna, K. C Hansen, Densities, Refractive Indices of Diethylene Glycol, Dimethyl Ether with Ethyl Acetate, Methyl Benzoate, Ethyl Benzoate, and Dimethyl Succinate in the Temperature Range from 298.15 to 318.15 K, J. Chem. Eng. Data. $39,1994,251-260$.

[18] A. Z. Tasic, B. D. Djordjevic, D. K. Grozanic, N. Radojkovic, Use of Mixing Rules in Predicting Refractive Indices and Specific Refractivities for some Binary Liquid Mixtures, J. Chem. Eng. Data. 37, 1992, 310313.

[19] S. S. Jr. Kurtz, A. L. Ward, The refractivity intercept and the specific refraction equation of Newton. I. Development of refractivity intercept and comparison with specific refraction equations, J. Franklin. Inst, 222, 1936, 563-592.

[20] S. C. Bhatia, N. Tripathi, G. P. Dubey, Refractive index of binary liquid mixtures of decane + benzene and hexadecane + benzene or + hexane at $303.15 \mathrm{~K}, 308.15 \mathrm{~K}$ and 313.15K, Indian J. Chem, 41A, 2002, 266-269.

[21] R. Mehra, Application of refractive index mixing rules in binary systems of hexadecane and heptadecane with n-alkanols at different temperatures, Proc. Indian Acad. Sci, Chem. Sci, 115 (2), 2003, 147-153.

[22] K. Navendra, P. Narayanamurthy, Ch. Srinivasu, Refractive indices of binary liquid mixtures at different temperatures, Asian. J. App. Sci, 4, 2011, 535-541.

[23] S. O. Isehunwa, E. B. Oianisebe, O. O. Ajiboye, S. A. Akintola, Estimation of the refractive indices of some binary mixtures, Afri. J. Pur. Appl. Chem, 9(4), 2015, 58-64.

[24] M. V. Rathnam, S. Mohite, M. Nandini, Excess properties of diethyl carbonate + ketone binary mixtures at variable temperatures: Application of PFP theory to excess volumes, J. Mol. Liq, 177, 2013, 229236. 
Table 1: Mole Fraction $\left(x_{1}\right)$, Densities $(\rho)$, Excess Volumes $\left(V^{E}\right)$, Dynamic Viscosities $(\eta)$, Refractive Index $\left(n_{\mathrm{D}}\right)$ for the Binary Mixtures

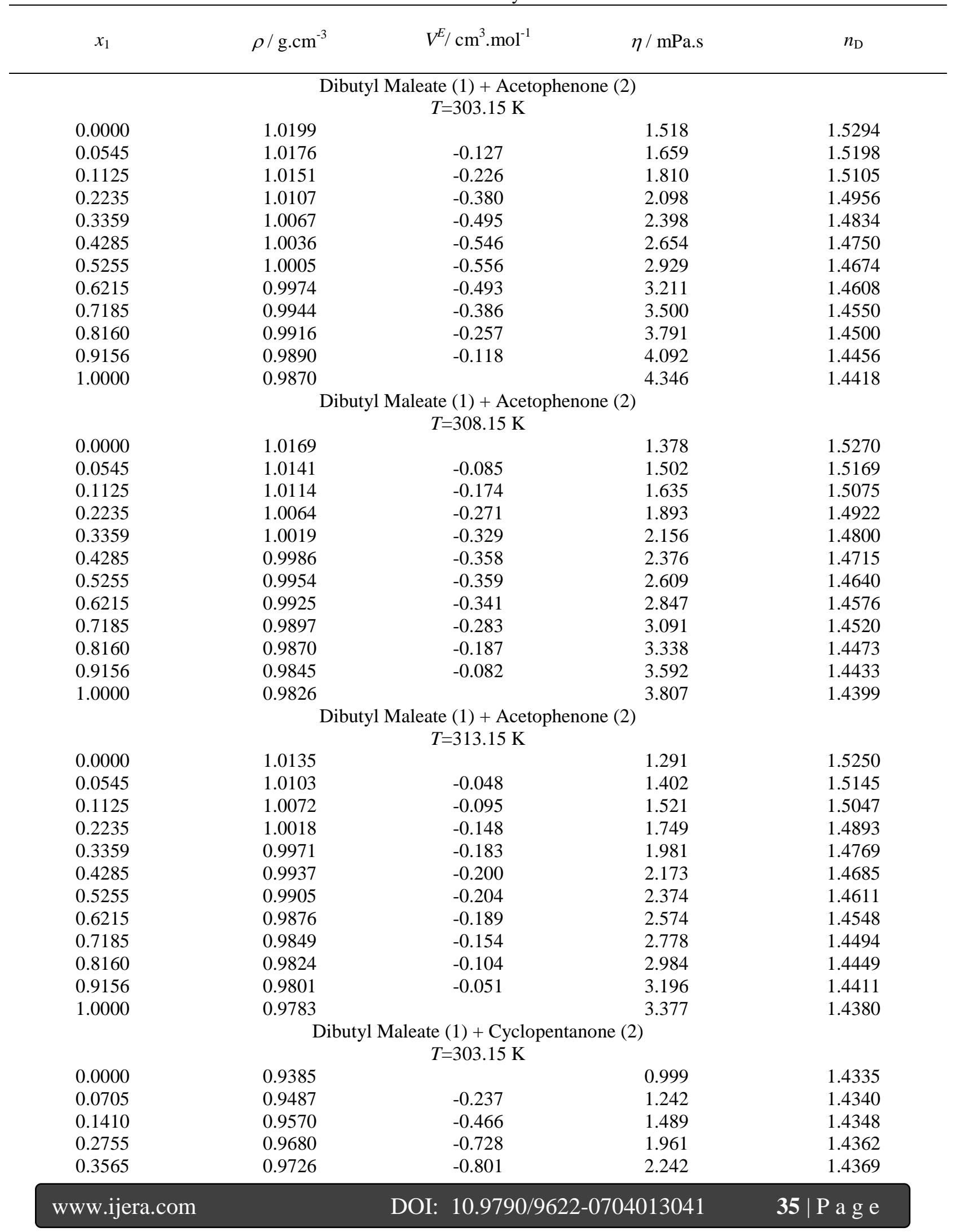




\begin{tabular}{lllll}
0.4418 & 0.9765 & -0.848 & 2.534 & 1.4376 \\
0.5318 & 0.9798 & -0.865 & 2.834 & 1.4384 \\
0.6318 & 0.9826 & -0.827 & 3.161 & 1.4391 \\
0.7398 & 0.9846 & -0.675 & 3.510 & 1.4399 \\
0.8416 & 0.9857 & -0.423 & 3.836 & 1.4407 \\
0.9150 & 0.9862 & -0.197 & 4.072 & 1.4412 \\
1.0000 & 0.9870 & 4.346 & 1.4418 \\
\multicolumn{5}{c}{ Dibutyl Maleate $(1)+$ Cyclopentanone $(2)$} \\
0.0000 & $0.9308 .15 \mathrm{~K}$ & 0.927 & 1.4310 \\
0.0705 & 0.9339 & -0.279 & 1.145 & 1.4315 \\
0.1410 & 0.9445 & -0.499 & 1.363 & 1.4322 \\
0.2755 & 0.9527 & -0.763 & 1.772 & 1.4337 \\
0.3565 & 0.9637 & -0.865 & 2.016 & 1.4346 \\
0.4418 & 0.9685 & -0.914 & 2.265 & 1.4363 \\
0.5318 & 0.9724 & -0.933 & 2.525 & 1.4370 \\
0.6318 & 0.9757 & -0.878 & 2.805 & 1.4378 \\
0.7398 & 0.9784 & -0.726 & 3.100 & 1.4387 \\
0.8416 & 0.9804 & -0.473 & 3.376 & 1.4392 \\
0.9150 & 0.9815 & -0.245 & 3.576 & 1.4399 \\
1.0000 & 0.9820 & 0.907 & 3.807 &
\end{tabular}

Dibutyl Maleate (1) + Cyclopentanone (2)

$$
T=313.15 \mathrm{~K}
$$

0.0000

0.9290

0.9398

0.1410

0.9482

0.2755

0.9594

0.3565

0.9642

0.4418

0.9681

0.5318

0.9713

0.9741

0.7398

0.9763

0.8416

0.9150

0.9775

0.9780

$-0.293$

0.865

1.4290

1.0000

0.9783

$-0.531$

1.062

1.4292

1.4299

1.4315

1.4324

$-0.911$

1.620

1.4334

$-0.955$

1.835

2.054

$-0.952$

2.280

1.4342

1.4350

1.4358

$-0.788$

2.520

2.773

$-0.551$

1.4365

1.4371

1.4380

Dibutyl Maleate (1) + Cyclohexanone (2)

$$
T=303.15 \mathrm{~K}
$$

0.0000

0.9377

0.0471

0.9443

0.9506

0.1002

0.9599

0.3097

0.9675

0.9724

0.9767

0.5035

0.9800

0.6038

0.9824

0.8024

0.9842

0.9135

0.9859

1.0000

0.9870

1.816

1.4465

$-0.205$

1.965

1.4464

1.4462

1.4456

$-0.620$

2.135

2.455

1.4447

$-0.782$

2.790

3.051

1.4442

$-0.843$

1.4437

$-0.792$

1.4433

3.539

1.4428

$-0.632$

3.754

1.4424

$-0.449$

3.956

1.4420

4.177

1.4418 
Dibutyl Maleate (1) + Cyclohexanone (2)

0.0000

0.0471

0.1002

0.2012

0.3097

0.4013

0.5035

0.6038

0.7066

0.8024

0.9135

1.0000

0.0000

0.0471

0.1002

0.2012

0.3097

0.4013

0.5035

0.6038

0.7066

0.8024

0.9135

1.0000

0.0000

0.0508

0.1135

0.2135

0.3133

0.4052

0.5078

0.6065

0.7152

0.8098

0.9185

1.0000

0.0000

0.0508

0.1135

0.2135

0.3133

0.4052

0.5078

0.6065

0.7152

$$
T=308.15 \mathrm{~K}
$$

$\begin{array}{ll}0.9328 & -0.225 \\ 0.9396 & -0.420 \\ 0.9460 & -0.671 \\ 0.9555 & -0.813 \\ 0.9630 & -0.901 \\ 0.9681 & -0.900 \\ 0.9724 & -0.841 \\ 0.9757 & -0.714 \\ 0.9783 & -0.528 \\ 0.9801 & -0.236 \\ 0.9816 & \\ 0.9826 & T=313.15 \mathrm{~K}\end{array}$

0.9282

0.9352

0.9417

0.9512

0.9588

0.9638

0.9683

0.9716

0.9742

0.9760

0.9774

0.9783

Dibutyl Maleate (1) + 3-Pentanone (2)

1.657

1.4440

1.798

1.4439

1.4436

1.4430

1.4423

1.4420

1.4415

1.4411

1.4408

1.4405

1.4401

1.4399

3.807

3.361

3.517

$=313.15 \mathrm{~K}$

1.4420

1.4419

1.4416

1.4410

1.4404

1.4400

1.4396

1.4392

1.4389

1.4386

1.4382

1.4380

$$
T=303.15 \mathrm{~K}
$$

0.8057

0.8256

0.8473

0.8763

0.9000

0.9182

0.9353

0.9491

0.9619

0.9714

0.9807

0.9870

Dibutyl Maleate (1) + 3-Pentanone (2)

$-0.149$

0.429

1.3879

1.3925

1.3976

1.4045

1.4103

1.4154

1.4207

1.4256

1.4305

1.4345

1.4388

1.4418 $T=308.15 \mathrm{~K}$

0.8017

0.8214

0.8428

0.8718

0.8954

0.9136

0.9306

0.9444

0.9572

-0.130
-0.270
-0.490
-0.632
-0.717
-0.732
-0.688
-0.561

0.397

1.3857

1.3900

1.3949

1.4019

1.4078

1.4129

1.4182

1.4230

1.4281 
M.V. Rathnam et al. Int. Journal of Engineering Research and Application

www.ijera.com ISSN : 2248-9622, Vol. 7, Issue 4, ( Part -1) April 2017, pp.30-41

\begin{tabular}{|c|c|c|c|c|}
\hline 0.8098 & 0.9667 & -0.393 & 2.858 & 1.4322 \\
\hline 0.9185 & 0.9761 & -0.143 & 3.404 & 1.4366 \\
\hline 1.0000 & 0.9826 & & 3.807 & 1.4399 \\
\hline \multicolumn{5}{|c|}{$\begin{array}{c}\text { Dibutyl Maleate (1) + 3-Pentanone (2) } \\
T=313.15 \mathrm{~K}\end{array}$} \\
\hline 0.0000 & 0.7977 & & 0.388 & 1.3835 \\
\hline 0.0508 & 0.8171 & -0.095 & 0.466 & 1.3874 \\
\hline 0.1135 & 0.8382 & -0.198 & 0.566 & 1.3920 \\
\hline 0.2135 & 0.8669 & -0.377 & 0.745 & 1.3990 \\
\hline 0.3133 & 0.8904 & -0.502 & 0.951 & 1.4051 \\
\hline 0.4052 & 0.9086 & -0.585 & 1.167 & 1.4103 \\
\hline 0.5078 & 0.9256 & -0.597 & 1.457 & 1.4156 \\
\hline 0.6065 & 0.9394 & -0.548 & 1.782 & 1.4205 \\
\hline 0.7152 & 0.9522 & -0.415 & 2.185 & 1.4256 \\
\hline 0.8098 & 0.9618 & -0.262 & 2.582 & 1.4297 \\
\hline 0.9185 & 0.9716 & -0.097 & 3.039 & 1.4344 \\
\hline 1.0000 & 0.9783 & & 3.377 & 1.4380 \\
\hline
\end{tabular}

Table 2: Derived Parameters of equation (3) for various functions and standard deviation of the binary mixtures at $(303.15,308.15$ and 313.15$) \mathrm{K}$

\begin{tabular}{|c|c|c|c|c|c|c|}
\hline Function & $T / \mathrm{K}$ & $A_{\mathrm{o}}$ & $A_{1}$ & $A_{2}$ & $A_{3}$ & $\sigma$ \\
\hline \multicolumn{7}{|c|}{ Dibutyl Maleate (1) + Acetophenone (2) } \\
\hline \multirow[t]{3}{*}{$V^{\mathrm{E}}$} & 303.15 & -0.9715 & 0.4201 & -0.8418 & 5.699 & 0.009 \\
\hline & 308.15 & 0.2476 & 0.2794 & -1.8409 & 7.9291 & 0.008 \\
\hline & 313.15 & -0.0849 & 0.1404 & -0.7692 & 3.3835 & 0.004 \\
\hline \multirow[t]{3}{*}{$\Delta \eta$} & 303.15 & -0.4982 & 0.0489 & 0.3307 & -0.9116 & 0.001 \\
\hline & 308.15 & -0.0740 & 0.0132 & -0.0576 & 0.4788 & 0.001 \\
\hline & 313.15 & -0.0104 & -0.0095 & -0.0546 & 0.1909 & 0.000 \\
\hline \multicolumn{7}{|c|}{ Dibutyl Maleate (1) + Cyclopentanone (2) } \\
\hline \multirow[t]{3}{*}{$V^{\mathrm{E}}$} & 303.15 & -3.5219 & -0.1547 & 0.1831 & 1.2517 & 0.016 \\
\hline & 308.15 & -3.7546 & -0.1593 & -0.0689 & 1.1444 & 0.008 \\
\hline & 313.15 & -3.8683 & 0.0134 & -0.7704 & 0.2469 & 0.009 \\
\hline \multirow[t]{3}{*}{$\Delta \eta$} & 303.15 & 0.2229 & -0.0326 & -0.1479 & 0.0597 & 0.001 \\
\hline & 308.15 & 0.2653 & -0.0425 & -0.0977 & 0.0037 & 0.001 \\
\hline & 313.15 & 0.3147 & -0.0557 & -0.0907 & -0.0040 & 0.001 \\
\hline \multicolumn{7}{|c|}{ Dibutyl Maleate (1) + Cyclohexanone (2) } \\
\hline \multirow[t]{3}{*}{$V^{\mathrm{E}}$} & 303.15 & -2.0499 & 0.3746 & 0.8162 & -0.2328 & 0.010 \\
\hline & 308.15 & -2.7778 & 0.2711 & 1.1174 & -0.1345 & 0.008 \\
\hline & 313.15 & -3.3766 & -0.4111 & 0.6939 & 0.2930 & 0.009 \\
\hline \multirow[t]{3}{*}{$\Delta \eta$} & 303.15 & -0.4104 & -0.9386 & 1.1420 & -0.8287 & 0.007 \\
\hline & 308.15 & -0.4523 & -0.9790 & 1.0194 & -0.6360 & 0.005 \\
\hline & 313.15 & -0.5040 & -1.0118 & 0.7944 & -0.5222 & 0.005 \\
\hline \multicolumn{7}{|c|}{ Dibutyl Maleate (1) + 3-Pentanone (2) } \\
\hline \multirow[t]{3}{*}{$V^{\mathrm{E}}$} & 303.15 & -3.1980 & 0.0377 & 0.3699 & 0.4270 & 0.006 \\
\hline & 308.15 & -2.9656 & 0.1482 & 0.7807 & 0.3528 & 0.010 \\
\hline & 313.15 & -2.3992 & 0.2964 & 1.1603 & 0.1763 & 0.005 \\
\hline \multirow[t]{3}{*}{$\Delta \eta$} & 303.15 & -2.8014 & 0.0603 & 0.7277 & 0.0130 & 0.005 \\
\hline & 308.15 & -2.2608 & -0.0013 & 0.6508 & 0.2329 & 0.002 \\
\hline & 313.15 & -1.7979 & 0.0334 & 0.5781 & 0.2472 & 0.003 \\
\hline
\end{tabular}


Table 3: Adjustable Parameters and Percentage Standard Deviation $\sigma(\%)$ of correlations for the Viscosities of

Table 4: Average Percentage Deviation (APD) in the Refractive Index from Different Mixing Relations

\begin{tabular}{lcccc}
\hline \multirow{2}{*}{ System } & $\mathrm{T} / \mathrm{K}$ & Lorentz-Lorentz & Weiner & Newton \\
\cline { 3 - 5 } & & APD & APD & APD \\
\hline Dibutyl Maleate (1)+ & 303.15 & 0.052 & 0.041 & 0.191 \\
Acetophenone (2) & 308.15 & 0.101 & 0.071 & 0.286 \\
& 313.15 & 0.139 & 0.096 & 0.362 \\
Dibutyl Maleate (1)+ & 303.15 & 0.055 & 0.034 & 0.106 \\
Cyclopentanone (2) & 308.15 & 0.062 & 0.038 & 0.119 \\
& 313.15 & 0.073 & 0.045 & 0.142 \\
Dibutyl Maleate (1)+ & 303.15 & 0.021 & 0.013 & 0.041 \\
Cyclohexanone (2) & 308.15 & 0.016 & 0.010 & 0.030 \\
& 313.15 & 0.015 & 0.010 & 0.030 \\
Dibutyl Maleate (1) + & 303.15 & 0.146 & 0.095 & 0.310 \\
3-Pentanone (2) & 308.15 & 0.170 & 0.110 & 0.356 \\
& 313.15 & 0.201 & 0.130 & 0.413 \\
\hline
\end{tabular}

Table 5: Parameters of the Pure Components used in PFP theory calculations at $(303.15,308.15$ and 313.15) K

\begin{tabular}{ccccccc}
\hline Component & $T / \mathrm{K}$ & $10^{4} \alpha / \mathrm{K}^{-1}$ & $\begin{array}{c}10^{4} K_{\mathrm{T}} / \\
\mathrm{MPa}^{-1}\end{array}$ & $\tilde{v}$ & $P^{*} / \mathrm{J} \mathrm{cm}^{-3}$ & $V^{*} / \mathrm{cm}^{3} \cdot \mathrm{mol}^{-1}$ \\
\hline Dibutyl Maleate & 303.15 & 8.29 & 67.0 & 1.2146 & 55.33 & 190.43 \\
& 308.15 & 8.32 & 68.9 & 1.2183 & 55.23 & 190.71 \\
Acetophenone & 313.15 & 8.36 & 70.8 & 1.2222 & 55.23 & 190.94 \\
& 303.15 & 5.81 & 22.4 & 1.1574 & 105.32 & 101.79 \\
& 308.15 & 5.83 & 23.0 & 1.1602 & 105.13 & 101.84 \\
Cyclopentanone & 313.15 & 5.85 & 23.6 & 1.1630 & 104.98 & 101.94 \\
& 303.15 & 10.83 & 38.6 & 1.2681 & 136.77 & 70.68 \\
Cyclohexanone & 308.15 & 10.89 & 39.8 & 1.2729 & 136.61 & 70.76 \\
& 313.15 & 10.95 & 41.0 & 1.2777 & 136.53 & 70.87 \\
& 303.15 & 9.45 & 37.9 & 1.2396 & 116.15 & 84.44 \\
3-Pentanone & 308.15 & 9.49 & 39.0 & 1.2438 & 115.99 & 84.60 \\
& 313.15 & 9.54 & 40.1 & 1.2481 & 116.06 & 84.72 \\
& 303.15 & 9.93 & 46.3 & 1.2497 & 101.54 & 85.54 \\
& 308.15 & 9.98 & 47.7 & 1.2541 & 101.40 & 85.66 \\
& 313.15 & 10.03 & 49.3 & 1.2586 & 100.92 & 85.79 \\
\hline
\end{tabular}


Table 6 Calculated Values of Three Contributions of the PFP Theory to Excess Volume at $(303.15,308.15$ and

\begin{tabular}{|c|c|c|c|c|c|c|c|}
\hline \multirow[t]{2}{*}{ System } & \multirow[t]{2}{*}{$T / \mathrm{K}$} & \multirow[t]{2}{*}{$\begin{array}{l}\chi_{12} / \\
\text { J.cm }\end{array}$} & \multicolumn{2}{|c|}{$\begin{array}{c}V^{E} / \mathrm{cm}^{3} \cdot \mathrm{mol}^{-1} \text { at } \\
\left(x_{1}=x_{2}=0.5\right)\end{array}$} & \multicolumn{3}{|c|}{ Calculated contributions $/ \mathrm{cm}^{3} \cdot \mathrm{mol}^{-1}$} \\
\hline & & & Experimental & PFP & $\begin{array}{c}\text { Interactional } \\
V^{E}{ }_{(\mathrm{int})}\end{array}$ & $\begin{array}{c}\text { Free } \\
\text { Volume } \\
V_{(\text {fv) }}^{E}\end{array}$ & $\begin{array}{c}P^{*} \text { effect } \\
V_{(\text {(ip) }}^{E}\end{array}$ \\
\hline Dibutyl Maleate & 303.15 & 0.8133 & -0.556 & -0.545 & 0.00089 & 0.00390 & -0.00050 \\
\hline$(1)+$ & 308.15 & 2.2233 & -0.359 & -0.372 & 0.00092 & 0.00403 & -0.00052 \\
\hline Acetophenone (2) & 313.15 & 3.5429 & -0.204 & -0.207 & 0.00094 & 0.00418 & -0.00054 \\
\hline Dibutyl Maleate & 303.15 & -2.5453 & -0.865 & -0.914 & 0.00110 & 0.00343 & -0.00057 \\
\hline$(1)+$ & 308.15 & -2.7605 & -0.933 & -0.982 & 0.00113 & 0.00358 & -0.00060 \\
\hline $\begin{array}{c}\text { Cyclopentanone } \\
\text { (2) }\end{array}$ & 313.15 & -2.8940 & -0.952 & -1.034 & 0.00116 & 0.00370 & -0.00062 \\
\hline Dibutyl Maleate & 303.15 & -4.9241 & -0.847 & -0.885 & 0.00113 & 0.00075 & -0.00011 \\
\hline$(1)+$ & 308.15 & -5.1717 & -0.900 & -0.950 & 0.00116 & 0.00078 & -0.00011 \\
\hline $\begin{array}{c}\text { Cyclohexanone } \\
\text { (2) }\end{array}$ & 313.15 & -5.3670 & -0.961 & -1.008 & 0.00119 & 0.00081 & -0.00012 \\
\hline Dibutyl Maleate & 303.15 & -3.3316 & -0.798 & -0.793 & 0.00122 & 0.00147 & -0.00017 \\
\hline$(1)+$ & 308.15 & -2.7734 & -0.732 & -0.722 & 0.00125 & 0.00154 & -0.00018 \\
\hline 3-Pentanone (2) & 313.15 & -1.8022 & -0.597 & -0.569 & 0.00129 & 0.00158 & -0.00019 \\
\hline
\end{tabular}

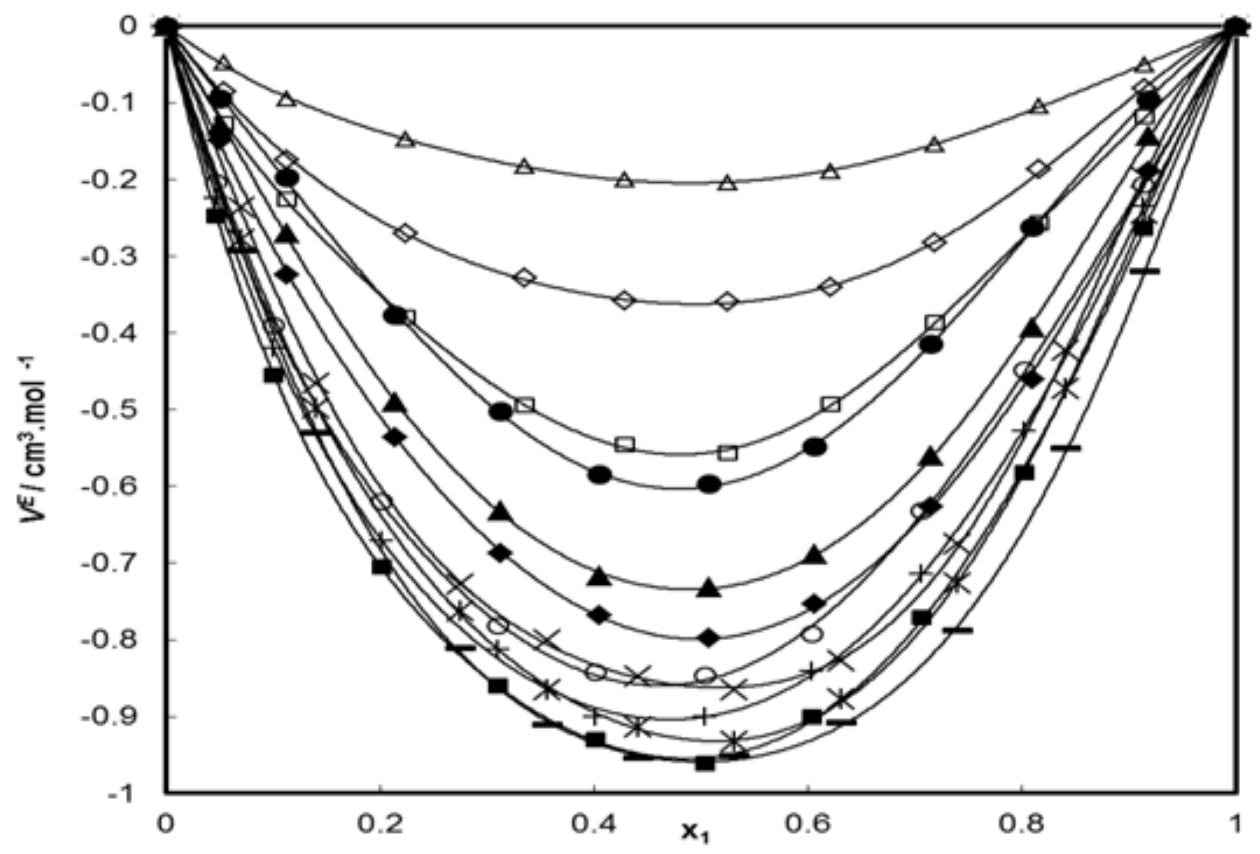

Fig. 1 Excess Volume, $V^{E}$ as a function of Dibutyl Maleate mole fraction, $x_{1}$ (Dibutyl Maleate + acetophenone): (口), at $303.15 \mathrm{~K} ;(\diamond)$, at $308.15 \mathrm{~K} ;(\Delta)$, at $313.15 \mathrm{~K}$. (Dibutyl Maleate + cyclopentanone): (X), at $303.15 \mathrm{~K} ;\left({ }^{*}\right)$, at $308.15 \mathrm{~K} ;(-)$, at $313.15 \mathrm{~K}$. (Dibutyl Maleate + cyclohexanone): (O), at $303.15 \mathrm{~K} ;(+)$, at $308.15 \mathrm{~K} ;(\mathbf{-})$, at $313.15 \mathrm{~K}$. (Dibutyl Maleate + 3-pentanone) :( , at $303.15 \mathrm{~K} ;(\boldsymbol{\Delta})$, at $308.15 \mathrm{~K} ;(\bullet)$, at $313.15 \mathrm{~K}$. 


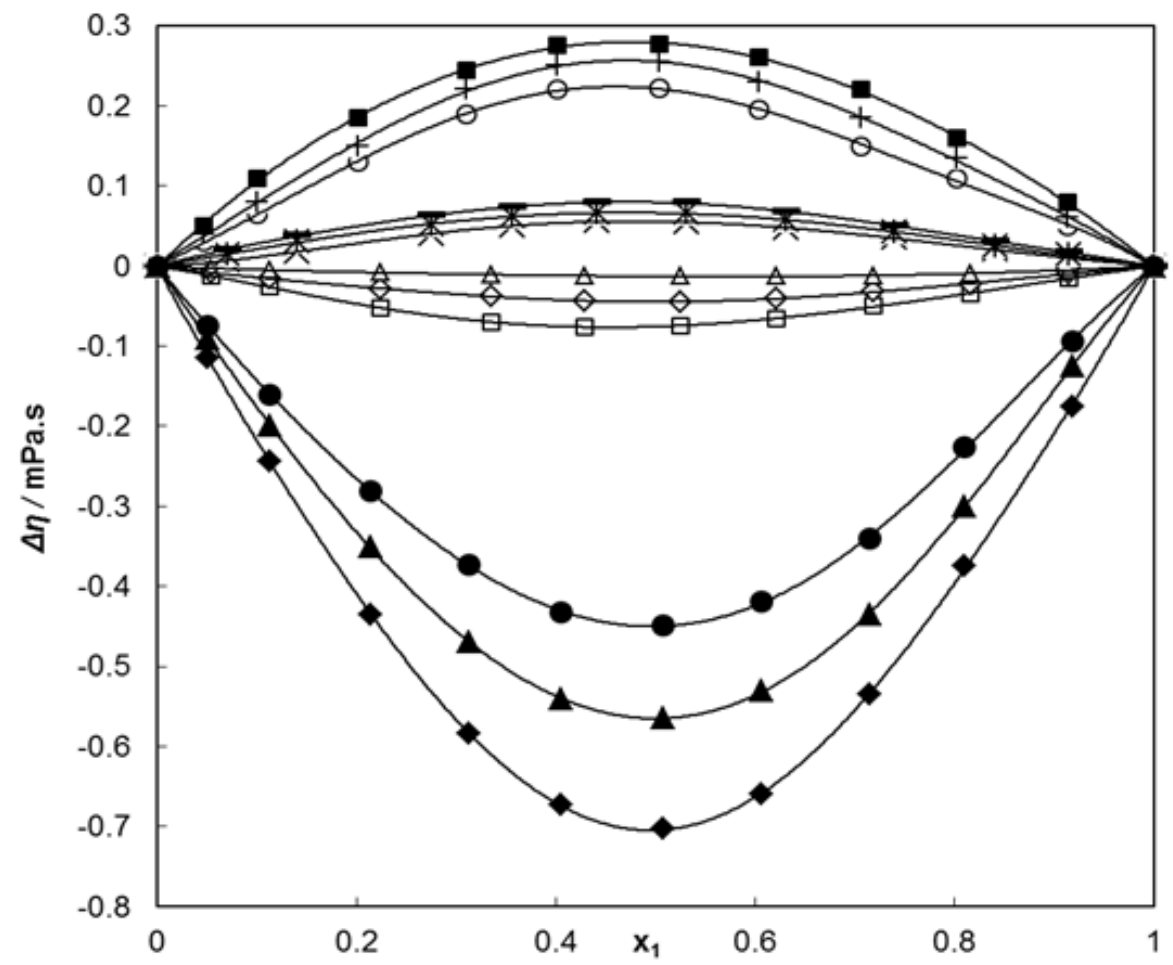

Fig. 2 Deviations in viscosity, $\Delta \eta$ as a function of Dibutyl Maleate mole fraction, $x_{1}$ (Dibutyl Maleate + acetophenone): (口), at $303.15 \mathrm{~K} ;(\diamond)$, at $308.15 \mathrm{~K} ;(\Delta)$, at $313.15 \mathrm{~K}$. (Dibutyl Maleate + cyclopentanone): (X), at $303.15 \mathrm{~K}$; (*), at $308.15 \mathrm{~K} ;(-)$, at $313.15 \mathrm{~K}$. (Dibutyl Maleate + cyclohexanone): (O), at $303.15 \mathrm{~K} ;(+)$, at $308.15 \mathrm{~K} ;(\mathbf{\bullet})$, at $313.15 \mathrm{~K}$. (Dibutyl Maleate + 3-pentanone) :( $\bullet$, at $303.15 \mathrm{~K} ;(\boldsymbol{\Delta})$, at $308.15 \mathrm{~K} ;(\bullet)$, at $313.15 \mathrm{~K}$. 